Nigerian Journal Of Physiological Sciences 21 (1-2): 83-89@ Physiological Society Of Nigeria, 2006.

Available online/abstracted at http://www.biolineinternational.org.br/njps; www.ajol.info/journals.njps; www.cas.org

\title{
THYROID HORMONE: THE MODULATOR OF ERECTILE FUNCTION IN THE RABBIT.
}

\author{
K. AMADI, M. A. SABO and A. S. SAGAY ${ }^{1}$ \\ Departments of Human Physiology and Obstetrics and Gynecology ${ }^{1}$ Faculty of Medical Sciences, \\ University of Jos, P.M.B 2084, Jos, Nigeria.
}

\begin{abstract}
Summary: The possible role of thyroid hormones in the Nitric Oxide (NO)- mediated response to sexual stimulation, and on prostaglandin $\mathrm{E}_{1}\left(\mathrm{PGE}_{1}\right)$ and Sildenafil in the treatment of erectile dysfunction was investigated using the corpus cavernosum of the New Zealand rabbit animal model. The parameters studied were penile erection monitored as contractile force of the erectile tissue, sperm count and motility; in parallel with the haematocrit, red cell count or rheology, Heart Rate (HR), Mean Arterial Pressure (MAP), Thyroid Stimulating Hormones (TSH) and Thyroixine levels. Hypothyroidism or thyroidectomy was found to cause depletion of Endothelium Derived Relaxant Factor (EDRF) thereby causing very feeble contraction of the cavernosum muscle, in both Prostaglandin $\mathrm{E}_{1}\left(\mathrm{PGE}_{1}\right)$ and Sildenafil, oligospermia and less than $45 \%$ motile sperms. Thyroxine treatment produced contraction proportionate to the concentrations of $\mathrm{PGE}_{1}$ and Sildenafil; providing evidence that the erectogenic actions of both $\mathrm{PGE}_{1}$ and Sildenafil are possible only in the presence of adequate thyroid hormone level.
\end{abstract}

Key Words: Corpus Cavernosum, Contractility, Erection, $P G E_{1}$, Sildenafil.

\section{Introduction}

Erectile dysfunction is a known cause of impotence abnormal however, erectile dysfunction, impotence and abnormal sperm morphology can cause infertility. PadmaNathan et al (2001) found that erectile dysfunction is associated with behavioural risk factors like cigarette smoking, excessive intake of alcohol and other age-related medical conditions. Rajfer et al (1992) have reported phosphodiesterase - type $5\left(\mathrm{PGE}_{5}\right)$ to be a critical component of the Nitric oxide-cyclic Guanidine Monophosphate (NO-cGMB) signaling pathway responsible for the modulation of smooth muscle tone in the penis. The authors noted that inhibition of $\mathrm{PGE}_{5}$ magnifies the NO-mediated response to sexual stimulation, increasing intracellular concentrations of cGMP and thus maintaining penile erection. Sildenafil, an inhibitor of $\mathrm{PDE}_{5}$ is an effective treatment for erectile dysfunction (Padma-Nathan et al, 1998; Goldstein et al 1998, Dinsmore et al 1999). The inhibition of $\mathrm{PDE}_{5}$ would therefore be expected to result in improved contractile force.

Prostaglandin $\mathrm{E}_{1} \quad\left(\mathrm{PGE}_{1}\right)$ solutions for intravenous injection therapy have been reported to be superior or at least equal in efficiency when compared to other erectogenic agents (Lea, Bryson and Baffour, 1996). The problem of erectile dysfunction is still prevalent despite attempts by scientists to find a total cure for it. The subject therefore calls for further investigations to find out if the problem could be due to enzyme or hormonal malfunction, its imbalance or deficiency. The present investigation examines any possible role of thyroid hormone $\left(\mathrm{T}_{4}\right)$ in the erectile or contractile activity of the rabbit corpus cavernosum treated with $\mathrm{PGE}_{1}$ and with Sildenafil. It has been stated that the most important chemical mediator of cavernosal relaxation is Nitric oxide (NO), released directly from nonadrenergic noncholinergic (purinergic) nerve endings and from endothelium (Utkan et al, 2001).

Hence, the need to inhibit EDRF to asses whether the thyroid hormone could have any role in the tonic or contractile response of the erectile tissue in the animal models: Euthyroid control, Hypothyroid (T); Hyperthyroid (TT), throidectomized rabbit with subsequent thyroxine replacement (TTT).

\section{Materials and Methods}

Sexually mature male New Zealand Rabbits of weight range $2.5-3 \mathrm{~kg}$ and inbred at University of Jos Animal house were randomly placed into four groups: Group 1 or control (C). Group 2 or Thyroidectomized (T); Group 3 or Thyroidectomized Rabbits with subsequent thyroxine treatment (TTT) and Group 4 or Thyroxine-treated animals (TT). There were ten 
rabbits in each group and the groups were matched weight for weight.

Preparation of Animals

Thyroidectomized Rabbit: The animals were first anaesthetized as applied by Utkan et al(2001): Xylazinee $5 \mathrm{mg} / \mathrm{kg}$ body weight and Ketamine 20mg/kg (Sigma Chemical St. Louis. MO. USA) were given intramuscularly to each rabbit. As soon as the anesthesia took effect the animals were prepared for surgery. The hair at the site of the operation was shaved and disinfected. A skin incision of about $4 \mathrm{~cm}$ in length was made with a scalpel in the midline axis of the neck. The wound was dilated with blunt forceps until the thyroid gland was exposed. The muscles and other adhering tissue were separated from the gland and then using a thermocautery the gland was removed; while leaving the external parathyroids intact. The wound was carefully swabbed and sulphonomide introduced into it. The skin was then stitched with interrupted sutures, which were knotted securely. Postoperative treatment include the administration of prophylactic procaine-penicillin injection intraperitoneally for 5 days. After surgery the rabbits were fed on normal rabbit pellets for 60 days while tap water was allowed ad-libitum.

\section{Throidectomized Rabbits Treated with Thyroxine (TTT)}

This group underwent the same surgical process as described for the thyroidectomized rabbits. In addition the animals received par oral, constant dose of thyroxine (A.H Cox and Co. Ltd Barstaple England); $10 \mu \mathrm{g} / \mathrm{kg}$ body weight for 60 days. The thyroxine tablets were taken in tepid water on a hot plate, to bring the tablets into solution. By means of $1 \mathrm{ml}$ syringe attached to a canula, the dose was delivered dropwise around the oropharynx. This was effected by holding the upper incisors with a loop of strong thread tied to a water tap while the lower incisor teeth were held back by another loop tied to the thumb. After each administration of thyroxine the animals were also fed rabbit pellets and tap water allowed ad libitum for 60 days.

Thyroxine-Treated Rabbits (TT)

Thyroxine was administered at the same dose and method used for (TTT) to the group of euthyroid rabbits. They were similarly fed rabbit pellets and tap water for 60 days.

\section{Control Rabbits}

The animals in this group were given rabbit pellets and tap water was also allowed ad libitum for 60 days.

Contractile Studies. The preparation of the tissue for contractile studies was similar to the method applied by Utkan et al (2001). The
Corpora Cavernosa tissue comprissing four strips of corpus Cavernosum smooth muscle of each rabbit, euthanized by stunning, were dissected out of the penis; having made a ventral incision on the right and left corpora, to dissect the tunica.

From the corpus cavernosum tissue strips measuring $2 \times 2 \times 15 \mathrm{~mm}$ were studied under standard organ baths conditions: The strips were mounted vertically with silk thread between a fixed metal base on one end in a $20 \mathrm{ml}$ jacketed organ bath containing $10 \mathrm{ml}$ of physiological salt solution of the following composition (mMol/L): $\mathrm{NaCl}, 119.0, \mathrm{KCl} 4.7$, $\mathrm{KH}_{2} \mathrm{PO}_{4} 1.2, \mathrm{Mg} \mathrm{SO}_{4} 1.2, \mathrm{NaHCO}_{3} 24.9 \mathrm{CaCl}_{2}$ 1.6 glucose 11.5. The other end was connected to isometric force transducers (Grass FT. 03 Quincy, M.A). The temperature of the bath was maintained at $37^{\circ} \mathrm{C}$ by a thermostatically controlled water bath. The solution was bubbled with $95 \% \mathrm{O}_{2}: 5 \% \mathrm{CO}_{2}$ gas mixture; $\mathrm{pH} 7.40$. Change in isometric force was recorded on a Grass Model 7, 8-channel Polygraph pen recorder (Grass Instruments Ltd. Quincy Mass). During a 90 min equilibrium period, the tissue was exposed to three changes of Kreb's bicarbonate and resting tension adjusted to $2 \mathrm{~g}$, found to be optimal for measurement of changes in tension of rabbit corpus cavernosal preparation (Utkan et al (2001).

The strips except $(\mathrm{T})$ were exposed for 15 mins to $10 \mathrm{M}$ NG Monomethyl L-arginine (L-NMMA) a specific inhibitor of Nitric Oxide (NO) synthesis as applied by Ebeigbe and Aloamaka. (1999) and Aloamaka et al, (1999). This endothelium-derived relaxing factor (NO) has been reported to regulate vascular and smooth muscle tone (Kin et al, 1995; Rajfer et al, 1992; Obiefuna et al 1993. Lot and Wilson, 1992, Lot 1993). After exposure to L-NMMA the strip of Corpora Cavernosa were then subjected in groups in turn to graded doses of $\mathrm{PGE}_{1}$ and Sildenafil $\left(10^{-6}-3 \times 10^{-4} \mathrm{M}\right)$ in a cumulative manner.Contractile, responses in the four thyroid states: Control, Thyroidectomized. Thyroidectomized - treated with thyroxine, and Thyroxine treated, were recorded.

\section{Semen Analysis}

Semen examination was performed for sperm count and motility. To collect the Semen a rubber condom containing warm semen diluting fluid was quickly slipped on to the base of the penis of each rabbit, as soon as it protruded the penis, to mount a sexually mature female presented to it in a large cage. Composition of Semen diluting Fluid (Baker et al, 1994) was Sodium Bicarbonate $-5 \mathrm{~g}$, Formalin $-2 \mathrm{~cm}^{3}$, and distilled water $-100 \mathrm{~cm}^{3}$. Sperm Count: 
The technique employed was similar to that for counting blood cells on an improved Neubauer chamber. The sample was well mixed and a dilution made as for red blood cell count using the sperm diluting fluid. The chamber was charged and placed on a warm-stage microscope. After being allowed to settle, the heads of spermatozoa in the large corner squares and the entire central square were counted.

\section{Calculation:}

Let $\mathrm{N}=$ No of sperm counted in 5 large squares, Then $\mathrm{N} / 5=$ No of sperm in $1 \mathrm{sq} \mathrm{mm}, \mathrm{N}$ $15 \mathrm{x} 10=$ No of sperm in $1 \mathrm{~mm}^{3}$

This result multiplied by dilution factor $(1 / 200)=$ No of sperm per $\mathrm{mm}^{3}$ of semen. The number of sperm per $\mathrm{mm} 3$ was as multiplied by 1.000 to obtain the number per $\mathrm{cm} 3$. Again this figure was multiplied by the total volume of semen expressed in $\mathrm{cm}^{3}$ to obtain the number of sperm per ejaculate.

Motility

A cover-glass preparation in physiological saline was made to examine for motility. The slide was kept in an incubator at $36^{\circ} \mathrm{C}$ immediately before examination on a warm stage microscope set at $34^{0} \mathrm{C}$.

The types of motility were classified as:

1. Oscillatory or stationary hunting: the sperm do not move from place to place.

2. Undulating movement: with slow progression

3. Rapid, progressive, vibrating movement The system adopted for comparing degrees of motility was: $0=$ No discernible motility.; $1=$ Less than $50 \%$ motile, mostly weak and oscillatory; $2=$ More than $50 \%$ motile, vigorous, rapid waves or eddies; $3=90 \%$ motile, rapid waves and eddies.

$4=90 \%$ motile, rapid waves and eddies; $=100 \%$ motile, waves and eddies extremely rapid.
Counts In Sildenafil-Treated and Pge ${ }_{1}$-Treated Semen Fluid

Count and Motility in the four states were repeated in semen fluid containing $0.05 \mathrm{~mm}^{3}$ of Sildenafil and another treated with the same volume of $\mathrm{PGE}_{1}$.

\section{Statistics}

All results are expressed as Means \pm SEM, Statistical comparisons between the experimental groups were performed using the students' two-tailed test for unpaired data.

\section{Results}

Contractility: Contractile responses (in $\mathrm{PGE}_{1}$ and in sildenafil are shown in Figures 1 and 2) highlight the following. Thyroid hormones or thyroxine treatment produced robust constrictor actions without preconstriction after de-endotheliazation, suggesting thyroid hormone as an endogenous excitatory factor mediating constrictor actions of arginine analogues in vessels and corpus cavernosum smooth muscle. This was strongly indicated by the non-response of $\mathrm{PGE}_{1}$ in thyroidectomy. Both thyroxine treatment and thyroxine replacement after thyroidectomy exhibited identical response as control at a concentration of $2.4 \times 10^{-5} \mathrm{M} / \mathrm{L}$, thus prescribing the maximum beneficial dose in thyroid hormone treatments, for erectile function.

A similar safety margin is shown in Figure 2 by thyroxine treatment and control copora cavernosa graphs manifesting identical profile in sildenafil treatment. Contraction in thyroidectomy on the contrary was just lifted from the base line, depicting sildenafil action to be dependent on thyroid hormone level in the vicinity of the erectile tissue of the rabbit penis.

Table 1: Semen Analysis of Experimental Rabbits in Thyroidectomy and Thyroxine. Treatment. Sperm Count Mean $(X) \pm \operatorname{SEM}\left(X 10^{6} \mathrm{~mm}^{3}\right)$.

\begin{tabular}{cccccc}
\hline $\begin{array}{c}\text { Animal } \\
\text { Group: }\end{array}$ & $\mathrm{C}$ & $\mathrm{T}$ & $\mathrm{TTT}$ & $\mathrm{TT}$ & P-Value \\
\hline & 141 & 151 & 140 & 151 & $\mathrm{CV} * \mathrm{~T}$ \\
& 112 & 8 & 125 & 185 & $<0.001$ \\
& 186 & 10 & 200 & 120 & $\mathrm{CV} * \mathrm{TTT}$ \\
& 125 & 12 & 115 & 130 & $<0.5$ \\
& 102 & 14 & 125 & 111 & $\mathrm{CV} * \mathrm{TT}$ \\
& 191 & 75 & 150 & 80 & $<0.5$ \\
& 89 & 28 & 95 & 95 & $\mathrm{TTV} * \mathrm{~T}$ \\
& 150 & 9 & 108 & 170 & $<0.001$ \\
$\mathrm{X}$ & 145 & 50 & 115 & 65 & \\
& 110 & 30 & 145 & 80 & \\
& $136.1 \pm 10.9$ & $25.1 \pm 6.0$ & $121.8 \pm 14.97$ & $116.9 \pm 12.9$ &
\end{tabular}

Key $C=$ Control: $T=$ Thyroidectomized $: T T=$ Thyroxine-treated $: T T T=$ thyroidectomized-treatment with thyroxine. Number of animals in parenthesis, $P<0.05$ significant. Student $t-$ test $P<0.001 . n=10$ 
Table 2: Semen Analysis of Experimental Rabbits in Thyroidectomy and Thyroxine. Sperm Motality Mean $X \pm \operatorname{SEM}(\%)$.

\begin{tabular}{cccccc}
\hline $\begin{array}{c}\text { Animal } \\
\text { Group: }\end{array}$ & $\mathrm{C}$ & $\mathrm{T}$ & $\mathrm{TTT}$ & $\mathrm{TT}$ & P-Value \\
\hline & 3 & 0 & 2 & 4 & $\mathrm{CV}^{*} \mathrm{~T}$ \\
& 2 & 1 & 2 & 5 & $\mathrm{CV}^{*}$ \\
& 4 & 2 & 3 & 3 & $\mathrm{CV}^{*} \mathrm{TTT}$ \\
& 5 & 0 & 4 & 3 & \\
& 3 & 1 & 4 & 4 & CV*TT \\
$\mathrm{X}$ & $3.4 \pm 0.5$ & $* 0.8 \pm 0.37$ & $3 \pm 0.5$ & $3.8 \pm 0.4$ & $<0.5$
\end{tabular}

$\mathrm{C}=$ Control: $\mathrm{T}=$ Thyroidectomized: $T T T=$ Thyroidectomized treated with thyroxine $T$ T thyroxine treated Number of animals are in parenthesis. Scoring Scale $=0-5 ; 0=$ No discernible motility: 1-50\% motility, mostly weak and oscillatory; $250 \%$ motility. Vigorous. Rapid without waves or eddies: 3 75\% $85 \%$ motile, vigorous waves and eddies: $5=100$ motile, waves and eddies extremely rapid, $P<0.05$ as statistically significant $n=5$.

Tables 1, 2,3 , and 4 show that there was no significant difference in sperm count between control and thyroxine-treated rabbit whereas the difference exists between control and hypothyroid (thyroidectomized) rabbits $(\mathrm{P}<$ 0.001): and the same P-value between the two groups in sperm motility. There are also differences at $\mathrm{P}<0.025$ in red blood cell count and heart rate. There were no significant differences in haematocrit, mean arterial blood pressure (MAP); and Thyroxine $\left(\mathrm{T}_{4}\right)$ levels between each group and control. However, difference exist between Thyroxine treated (TT) and Thyroidectomized (T) rabbits in haematocrit, MAP and Heart Rate (HR), levels at $(\mathrm{P}<.0 .05)$. TSH for control and TT were also statistically different.

Table 3: Haematocrit, Red Blood Cell Count and mean Arterial Pressure of Experimental Rabbit Mean X SEM

\begin{tabular}{|c|c|c|c|c|c|c|c|c|c|c|c|c|}
\hline \multirow[t]{2}{*}{$\begin{array}{c}\text { Experimental } \\
\text { Animals }\end{array}$} & \multicolumn{4}{|c|}{ Haematocrit (\%) } & \multicolumn{4}{|c|}{ Red Blood Cell (x106) $\mathrm{mm}^{-}{ }^{3}$} & \multicolumn{3}{|c|}{$\begin{array}{l}\text { Mean Arterial Pressure } \\
\left(\mathrm{mm} 11_{2}\right)\end{array}$} & \multirow[b]{2}{*}{ TT } \\
\hline & $\mathrm{C}$ & $\mathrm{T}$ & TTT & TT & $\mathrm{C}$ & $\mathrm{T}$ & TTT & TT & $\mathrm{C}$ & $\mathrm{T}$ & TTT & \\
\hline 1 & 41 & 34 & 40 & 42 & 5.4 & 2.2 & 4.8 & 6.5 & 20 & 15 & 21 & 22 \\
\hline 2 & 40 & 25 & 38 & 40 & 4.9 & 3.4 & 5.0 & 7.0 & 2.5 & 14 & 19 & 20 \\
\hline 3 & 42 & 30 & 40 & 41 & 5.0 & 4.0 & 5.8 & 20 & 20 & 15 & 20 & 21 \\
\hline 4 & 39 & 38 & 41 & 42 & 5.2 & 3.0 & 5.0 & 6.0 & 20 & 16 & 16 & 20 \\
\hline 5 & 45 & 32 & 14 & 43 & 4.8 & 4.5 & 4.5 & 6.8 & 20 & 15 & 15 & 25 \\
\hline \multirow[t]{2}{*}{$\mathrm{X}$} & 41.4 & 29.8 & $* 40.0 \pm$ & $41.4 \pm 0$ & $5.06 \pm$ & $* 3.4 \pm$ & $4.76 \pm$ & $6.42 \pm$ & $21.01 \pm$ & $11.01 \pm$ & $11.01 \pm$ & $2.161 \pm$ \\
\hline & \pm 1.0 & \pm & 0.55 & .51 & 0.10 & 0.28 & 0.11 & 0.23 & & & & \\
\hline
\end{tabular}

$C=$ Control: $T=$ thyroidectomized $; T T=$ Thyroidectomized-treated with thyroxine, $T T=$ Thyroxinetreated Number of animals in parenthesis. $C V^{*} T, P<0.001$ for Haematocrit, $C V^{*} T \& P<0.001$ for $R B C$ $V^{*}=$ Compared with, $P<0.05 .(n=5)$ 
Table 4: Show Heart Rate, TSH \& T4 Levels of Experimental Animals Mean X \pm SEM

\begin{tabular}{|c|c|c|c|c|c|c|c|c|c|c|c|c|c|c|}
\hline \multirow{2}{*}{\multicolumn{2}{|c|}{$\begin{array}{l}\text { Experimental } \\
\text { Animals }\end{array}$}} & \multicolumn{4}{|c|}{ Heart Rate (beasts per minute) } & \multicolumn{4}{|c|}{$\begin{array}{l}\text { Thyroid Stimulating Hormone } \\
\text { (TSH) (u.ml) }\end{array}$} & \multicolumn{4}{|c|}{ Thyroxine (T) ng/Dl } & \multirow[t]{2}{*}{ P-Value } \\
\hline & & $\mathrm{C}$ & $\mathrm{T}$ & TTT & $\mathrm{TT}$ & $\mathrm{C}$ & $\mathrm{T}$ & TTT & TT & $\mathrm{C}$ & $\mathrm{T}$ & TTT & TT & \\
\hline 1 & (10) & 148 & 136 & 150 & 149 & 6.5 & 1.8 & 5.6 & .82 & 3.8 & 0.6 & 2.5 & 4.8 & $\begin{array}{l}\text { Heart Rate } \\
\mathrm{CV}^{\mathrm{s}} \mathrm{T}: \\
\mathrm{P}<0.001\end{array}$ \\
\hline 2 & (10) & 140 & 130 & 145 & 140 & 5.4 & 1.0 & 6.7 & 6.6 & 4.0 & 0.6 & 1.9 & 1.0 & \\
\hline 3 & (10) & 145 & 135 & 140 & 142 & 6.0 & 0.7 & 6.0 & 5.8 & 3.5 & 0.5 & 4.2 & 2.2 & $\begin{array}{l}\mathrm{CV}^{\mathrm{s}} \mathrm{TT}: \\
\mathrm{P}<0.50\end{array}$ \\
\hline 4 & (10) & 150 & 140 & 150 & 160 & 4.8 & 1.6 & 5.5 & 5.0 & 3.0 & 0.8 & 1.5 & 3.5 & FOR TSH \\
\hline 6 & $(10)$ & 145 & 120 & 138 & 140 & 5.8 & 0.8 & 4.5 & 6.8 & 2.8 & 0.5 & 2.0 & 4.0 & $\begin{array}{l}\mathrm{CV}^{\mathrm{s}} \mathrm{T}: \\
. \mathrm{P}<0.001\end{array}$ \\
\hline $\bar{X}$ & & $\begin{array}{c}145 \\
\pm \\
1.70\end{array}$ & $\begin{array}{c}112^{*} \\
\pm 19.60\end{array}$ & $\begin{array}{c}144.6 \pm \\
2.50\end{array}$ & $\begin{array}{l}146.2 \\
\pm 3.8\end{array}$ & $\begin{array}{c}5.7 \pm \\
0.3\end{array}$ & $\begin{array}{c}1.18 \\
\pm \\
0.2\end{array}$ & $\begin{array}{l}5.66 \\
\pm 0.4\end{array}$ & $\begin{array}{c}* * 6.48 \\
\pm 0.5\end{array}$ & $\begin{array}{c}2.42 \\
\pm \\
0.23\end{array}$ & $\begin{array}{c}0.6 \\
\pm \\
0.05\end{array}$ & $\begin{array}{c}2.42 \\
\pm \\
0.5\end{array}$ & $\begin{array}{c}3.16 \\
\pm \\
0.66\end{array}$ & $\begin{array}{l}\mathrm{CV}^{\mathrm{s}} \mathrm{TT}: \\
\mathrm{P}<0.001\end{array}$ \\
\hline
\end{tabular}

$C=$ Control $; T=$ thyroidectomized $; T T T=$ Thyroidectomized, treated with thyroxine, $T T=$ Thyroxine treated. Number of animals in parenthesis. Regard $P<0.05$ as significant, $V^{S}=$ compared with $* P<0.001 ; * * P<0.01$.

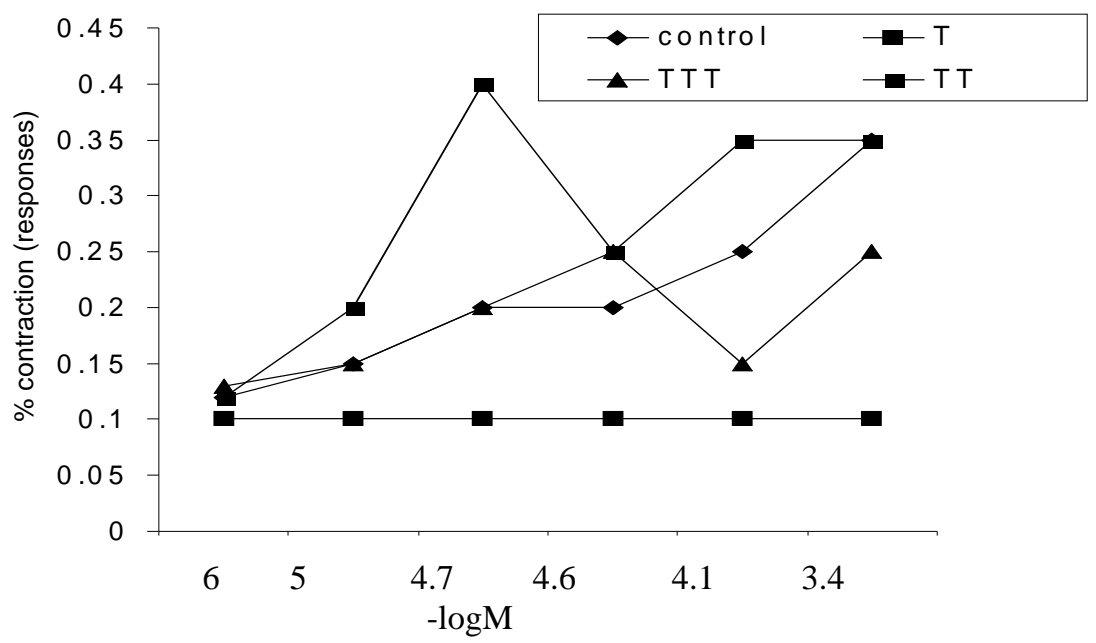

Fig. 1: Responses of Vasa deferentia in various thyroid states to PGE1 following inhibition of Nitric oxide.

\section{Discussion}

There are interesting findings in the present work, in hypothyroidism or thyroidectomy; there was no contraction of the vas deferens in PGE1 despite inhibition of Endothelium Derived Relaxation Factor (EDRF) by 10M NGL - NMMA. There was delayed but feeble short-lived contraction or increase in tone of the corpus cavernosum, the inhibition of $\mathrm{PDE}_{5}$ by sildenafil not withstanding (figures $1 \& 2$ ).
In spite of these inhibitions, thyrroxine $\left(\mathrm{T}_{4}\right)$ treatment in the affected groups gave robust contractions proportionate to the concentration of $\mathrm{PGE}_{1}$ and sildenafil respectively. Work on prostaglandin $\mathrm{E}_{2}\left(\mathrm{PGE}_{2}\right)$, an analogue of $\mathrm{PGE}_{1}$ had shown its contraction of the vas deferens smooth muscle to be dependent on the thyroid status of the animal( Amadi et al, 1996;1999). 


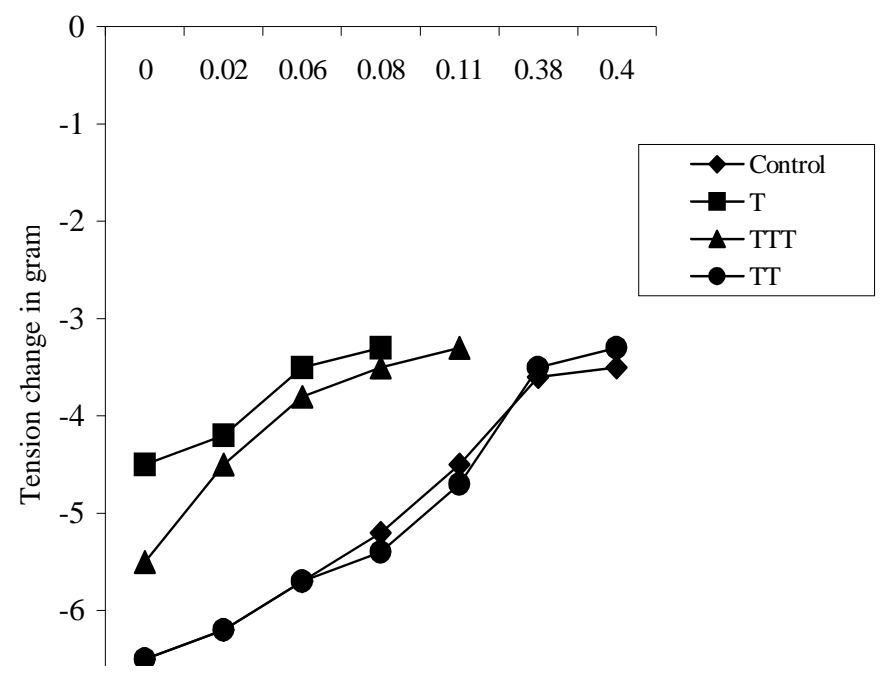

Fig.2: Responses of erectile tissue of rabbit penis to sildenafil.

In the present investigation the muscle tone produced by $\mathrm{PGE}_{1}$ in thyroxine treatment and the lack of contraction in thyroidectomy suggest that thyroxine is implicated in the erectogenic activity of $\mathrm{PGE}_{1}$. It would also appear that the endogenous excitatory factor mediating the constrictor actions of arginine analogues and prostaglandin $\mathrm{E}_{1}$ is thyroid hormone.

It is noteworthy that the responses were low inspite of thyroxine treatment (TTT). This was probably because, after removal of the thyroid gland, there was bound to be contraction hysteresis before thyroxine rehabilitation took effect within he time of study. The group had to depend on the secondary organs like salivary glands and gastric mucosa for trapping iodide for $T_{4}$ formation.

In hypothyroidism the non-contractile responses of the erectile tissue neither treated with EDRF inhibitor non-with sildenafil, an inhibitor of $\mathrm{PDE}_{5}$, were similar to response after the inhibitions. It is probable then that thyroidectomy or hypothyroidism depletes EDRF and thus inhibits the Nitric Oxide-cGMP pathway or potentiates $\mathrm{PDE}_{5}$ action. Sildenafil did not also produce increase in tone or tension of the hypothyroid rabbits.

Thyroxine on the other hand appears to inhibit $\mathrm{PDE}_{5}$ to activate the NO-cGMP 2nd messenger probably involving the thyroid adenyl cyclase by linking to the regulatory Gprotein. Thus the effectiveness of sildenafil from this study, in inhibiting $\mathrm{PDE}_{5}$ appears dependent on thyroid hormone.

As penile erection is a haemodynamic process involving relaxation of smooth muscle of Corpus cavernosum, depletion of EDRF by hypothyroidism could be responsible for the feeble contraction or non-relaxation of the muscle due to rigidity. Hypothyroidism has been reported to cause muscular atony (Goldstone and Ford, 1995: Amadi et al 1999). Thus, the lack of, or low tone prevents increased flow of blood into the trabecular spaces of the corpora cavernosa, to increase the vascular and muscle tone. The corporeal smooth muscle tone is important in the control of erection (Crist, 1995, Goldstein and Berman, 1998). This observation was represented by lower red blood cell count or quantity of blood flow, and motility in thyroidectomy, which impaired EDRF, which in turn is a major contributor to erectile dysfunction. These occurred with non-significant differences in $\mathrm{T}_{4}$ and MAP in all the groups, but TSH in TT.

It would be reasonable to conclude from the results of the present investigation that thyroid hormone is implicated in the activation of $\mathrm{PGE}_{1}$ and inhibition of $\mathrm{PDE}_{5}$ by Sildenafil. The erectogenic actions of $\mathrm{PGE}_{1}$ and sildenafil are thyroid dependent. It would thus be a very important factor for ameliorating eretile dysfunction. Erectile dysfunction parameters or tests should take cognizance of the thyroid hormone status of the animal. This is probably 
as observed presently that hypothyroidism (thyroidectomy) could be a factor in erectile dysfunction through the mechanism of deendothelization or depletion of Endothelium Derived Relaxation Factor (EDRF).

\section{Acknowledgement}

We are grateful to Funmilayo Raji (Mrs. F. Amadi ) God's Gift Business Centre for Secretarial expertise and to Arc. Tony Ogbonna for the professional diagrams.

\section{References}

Amadi, K,. Adeniyi, K. O., Nwana, E. J. C. and Otubu, J. A. M. (1996). Effect of Thyroxine and Potassium on the myometrium. Trop J. Obstet Gynae. 13 (1): 67-70.

Amadi, K., Nwana, E. J. C., Otubu, J. A. M. (1999). Effect of Thyroxine on the contractile responses of the Vas deference to Prostaglandin $\mathrm{E}_{2}$. Arch Androl. 42 55-62

Crist, G. J. (1995). The penis as vascular organ: the importance of corporeal smooth muscle tone in the control of erection. Urol Clin North Am. 22:727-745.

Dinsmore, W. W. (1999). Sildenafil citrate (Viagra) in erectile dysfunction: near normalization in men with broad-spectrum erectile dysfunction compared with agematched healthy control subject compared 53:800-805.

Ebiegbe, A. B., Idaewor, P. E. and Aloamaka, C. P. (1995). Attenuated Endotheliumdependent vascular relaxation in pregnancy-induced hypertension. Nig. J. Physiol Sic. (1-2): 32-33.

Glodstein, I., Berman, J. R. (1998). Vasculogenic Female sexual dysfunction; vaginal engorgement and clitoerial erectile insufficiency syndromes. Int. J. Impot Res. 1998; 10:84-90.

Goldstein, 1. (1998) Oral Sildenafil in the treatment of erectile dysfunction. New Engl. J. Med. 338: 1397-1404.

Goldstone, H. and Ford, F. R. (1991). Severe myotonia and complication of postoperative thyroid deficiency. Bull Johns Hopkins Hosp. 97:53-58.
Kim, S. G. (1995). A comparison of the relaxation responses of isolated cavernosal smooth muscle-dependent vasodilators in diabetic men with impotence. $J$ Korean Med. Sci. 10: 1-6.

Lea, A. P. Bryson, H. M., Balfour, J. A. (1996). Intracavernous alprostadil, A review of its pharmacodynamic and pharmacokinetic properties and therapeutic potential in erectile dysfunction. Drugs Aging . 8:5674.

Lot, T. Y. (1993). Inhibition of Nitric Oxide synthesis causes contraction and enhances phenylephrine-induced contraction of the porcine isolated splenic artery. Effects that are sensitive to flurbiprofen, A. A. 861 and BW 755. Nig. J. Physiol Sci. (1\&2): 67-73.

Lot, T. Y. and Wilson, V. G. (1993). Aminoguanidine, NG-Monomethyl L. arginine and NG-nitrol - L-arginine methyl ester causes endothelium dependent contractions of the porcine isolated splenic artery. Br. J. Pharmacol. 107: 284p.

Obiefuna, P. C. M., Sofola, O. A., and Ebeigbe, A. B. (1993). Relaxation of aortic rings from normotensive and salt-hypertensive rats to diltiazem, hydralazine and nifedipine. Nig. J. Physiol Sci. (1\&2): 6066.

Padma-Nathan, H., McMurray, J. G., Pullman, W. E., Whitaker, J. S., Sound, J. B., Ferguson, K. M. and Rosen, R. S. (2001). ON-demand IC351 (Cialis ${ }^{\mathrm{TM}}$ ) enhances erectile function in patients with erectile dysfunction. Int. J. Impot Res. 13: 2-9.

Padma-Nathan, H., Steers, W. D. Wicker, P. A. (1998). Efficacy and Safety of Oral Sildemafil in the treatment of erectile dysfunction: a double-blind, placebocontrolled study of 329 patients. Inc. J. Pract. 52:375-379.

Rajfer. J. (1992). Nitric Oxide as a mediator of relaxation of the corpus cavermosum in response to nonadrenergic nonehelinergic nuretransmission: New Engl. J. Med. 326: 90-94.

Utkan, T., Yildirim, M. K., Yildirim, S. and Sarioglu, Y. (2001). Effects of the specific phospodiesterase inhibitors on alloxaninduced diabetic rabbit cavernous tissue in vitro. Int. J. Impot Res. 13:24-30.

Received: $18 / 7 / 06$

Accepted:22/11/06 